\title{
Efeitos dos Programas Governamentais de Aquisição de Alimentos para a Agricultura Familiar em Espera Feliz, MG ${ }^{1}$
}

\author{
Wellington Alvim da Cunha², Alan Ferreira de Freitas ${ }^{3}$ e \\ Rafael Junior dos Santos Figueiredo Salgado ${ }^{4}$
}

Resumo: Este trabalho objetivou compreender os efeitos dos programas governamentais de aquisição de alimentos (PAA e PNAE) à dinâmica socioeconômica da agricultura familiar no município de Espera Feliz, em Minas Gerais. Questionou-se se os agricultores familiares estão mudando seus processos, dinâmicas e produtos em função das políticas de compra governamental. Para alcançar esses objetivos foram realizadas 61 entrevistas junto a agricultores fornecedores do PAA e PNAE. A pesquisa permitiu diagnosticar vários efeitos dos programas junto aos seus beneficiários, entre eles: i) Econômico: aumento de produção, trabalho e renda; diversificação produtiva e acesso a novos mercados; ii) Social: fortalecimento das organizações associativas locais, ampliação das relações institucionais, maior envolvimento familiar na produção; iii) Meio ambiente: o incentivo à produção livre de agrotóxico e iv) Segurança alimentar: melhoria na alimentação das famílias e aumento da qualidade dos produtos. Foi possível concluir que a identificação de efeitos em todas as categorias analisadas indica que os programas têm propiciado múltiplos efeitos positivos para a agricultura familiar local, imprimindo nova dinâmica social e econômica ao grupo de agricultores familiares que aderiram às compras institucionais.

Palavras-chaves: Agricultura familiar, políticas públicas, mercado institucional de alimentos.

Abstract: This work aims to understand the effects of government food acquisition programs (PAA and PNAE) on the socioeconomic dynamics of family farming in the municipality of Espera Feliz, in Minas Gerais State. It was questioned whether family farmers are changing their processes, dynamics and products according to government purchasing policies. To achieve these objectives, 61 interviews were carried out with farmers supplying the PAA and PNAE. The research allowed diagnosing various effects of the programs with their beneficiaries, among them: i) Economic:

1. Data de submissão: 12 de outubro de 2015. Data de aceite: 27 de abril de 2017.

2. Analista de formação da Central Cresol Baser, Muriaé, Minas Gerais-Brasil. E-mail: wellingtonalvimcunha@gmail.com

3. Professor da Universidade Federal de Viçosa, Viçosa-MG, Brasil. E-mail: freitasalan@yahoo.com.br

4. Doutorando em Administração pela Universidade Federal do Rio Grande do Norte. Natal (RN), Brasil. E-mail: rafa.salgad@gmail.com 
increase of production, work and income; Diversification of production and access to new markets; ii) Social: strengthening of local associative organizations, expansion of institutional relations, greater family involvement in production; iii) Environment: incentive to free production of pesticides and iv) Food security: Product quality. It was concluded that the identification of effects in all categories analyzed indicates that the programs have provided multiple positive effects for local family farming, imparting a new social and economic dynamics to the group of family farmers who joined institutional purchases.

Key-words: Family farming, public policy, institutional food market.

Classificação JEL: J38.

DOI: http://dx.doi.org/10.1590/1234-56781806-94790550301

\section{Introdução}

As desigualdades socioeconômicas são traços marcantes da sociedade brasileira e sua superação requer estratégias adequadas no sentido de direcionar prioritariamente o acesso a políticas públicas para indivíduos ou segmentos em situação de vulnerabilidade e risco social. Considerando-se essa conjuntura, as políticas públicas que enfocam determinados grupos sociais ganham destaque ao objetivarem a melhoria da qualidade de vida e a busca da solução de superação destes problemas. As políticas para a agricultura familiar no Brasil são um exemplo recente de delimitação da ação governamental a um público específico. O efeito destas políticas nas melhorias das condições de reprodução social no meio rural tem sido alvo de interesse de diversos pesquisadores a exemplo de Mattei (2007b), Grisa et al. (2011) e Schneider, Müller e Silva (2012), que buscaram entender as possíveis implicações das políticas empreendidas pelo Estado.

A agricultura familiar, a partir de 1990, ganhou reconhecimento do Estado brasileiro como importante categoria social e política. Essa mudança foi impulsionada pelas reivindicações de movimentos sociais do campo, pesquisas científicas e também pela relevância do setor para a economia nacional, principalmente quando se observa largo predomínio da agricultura familiar no Brasil, entre 70\% e 90\% dos estabelecimentos agropecuários, abrigando três quartos do pessoal ocupado no campo (KAGEYAMA, 2008). Contudo, em um passado recente, esse segmento foi relegado a segundo plano pelo Estado, pois vivenciara a competição desproporcional de condições e recursos com a grande produção e a grande propriedade. Essa ocorrência foi responsável por grandes impactos econô- micos e sociais no meio rural brasileiro, influenciando no aumento do êxodo rural, da pobreza, insegurança alimentar e interferindo na dinâmica populacional durante décadas (MARTINS, 1980).

Nesse contexto, o Estado brasileiro, a partir da metade da década de 1990, buscou atender às demandas dos agricultores familiares criando políticas públicas específicas de acesso ao crédito, terra, seguro agrícola, moradia, auxílio à comercialização, entre outros. Esse processo foi inaugurado de modo mais amplo a partir da criação do Programa Nacional de Fortalecimento da Agricultura Familiar (Pronaf), em 1995 (MATTEI, 2005). Concomitantemente a esse fenômeno, Cazella, Bonnal e Maluf (2009) apontam que a agricultura familiar passa ser discutida a partir das múltiplas funções, além da econômica, abarcando funções social, ambiental e de segurança alimentar, características conceituadas por muitos pesquisadores como multifuncionalidade da agricultura familiar.

A mudança de olhar sobre a agricultura familiar e os problemas do meio rural fizeram emergir um conjunto de novas ações governamentais a partir dos anos 2000, principalmente com o início do governo Lula, abrangendo características intersetoriais e que impactam em diversas funções da agricultura familiar. Estas ações são determinadas por Grisa e Schneider, (2014) como uma nova geração de políticas para a agricultura familiar, em que se destacam os programas de compra institucional de alimentos dos agricultores familiares, que cria cadeias curtas de comercialização e aproxima produtores e consumidores como forma de fortalecer a segurança alimentar e ampliar a renda dos produtores. Foram criados os Programas de Aquisição de Alimentos (PAA), em 2003, e o Programa Nacional de Alimentação Escolar (PNAE), em 2009, aliados à estra- 
tégia intersetorial de combate à fome e à pobreza por meio do Programa Fome Zero (PFZ) e das ações do plano Brasil Sem Miséria.

O PAA é considerado uma das principais ações estruturantes do PFZ, no qual o governo, seja na esfera federal, estadual ou municipal, adquire alimentos dos agricultores familiares e repassa para pessoas em situação de risco alimentar através de entidades conveniadas (MATTEI et al., 2011). A compra institucional de alimentos a partir do PAA tornou-se uma alternativa viável que visa, no âmbito do Ministério do Desenvolvimento Social e Combate à Fome (MDS), promover o acesso de alimentos às populações em situação de insegurança alimentar; proporcionar a inclusão social e econômica no campo e, por meio do fortalecimento da agricultura familiar através da compra da produção familiar, contribuir para formação de estoques estratégicos (MDS, 2014).

O Programa Nacional de Alimentação Escolar (PNAE) consiste na transferência de recursos financeiros do governo federal, via Fundo Nacional de Desenvolvimento da Educação (FNDE), aos estados, distrito federal e municípios, para a aquisição de gêneros alimentícios de qualidade, destinados aos alunos do Ensino Básico da rede pública. Seguindo a estratégia do PAA de conectar produção local ao consumo via mercado institucional, o programa foi reformulado em 2009, objetivando atender à demanda institucional com a oferta de produtos da agricultura familiar. A Lei n. 11.947, de 2009, instituiu novos parâmetros ao PNAE, em que, especificamente no artigo 14, incorporou um "novo" beneficiário do programa, com a determinação de que, do total dos recursos financeiros repassados pelo FNDE, no âmbito do PNAE, no mínimo 30\% deverão ser utilizados na aquisição de gêneros alimentícios da agricultura familiar e/ou de suas organizações (FNDE, 2014). Alguns autores, assim como Belik e Domene (2012), pontuam que existe uma conformidade entre os objetivos do PAA e do PNAE, uma vez que os programas exercem função de fomentar as ações de segurança alimentar e também o desenvolvimento da agricultura familiar. A conformidade se dá a partir da criação e expansão de um mercado institucional de alimentos para esse segmento, possibilitando a venda dos produtos às escolas públicas, equipamentos públicos de alimentação, entidades socioassistenciais com recursos do Estado. Os beneficiários desses programas podem ser classificados em dois grupos: os produtores de alimentos da agricultura familiar e os consumidores de alimentos (estudantes e usuários de entidades da rede socioassistencial).

Quanto aos beneficiários produtores da agricultura familiar observa-se, no Brasil, a emergência de uma nova realidade socioeconômica para os agricultores familiares após a criação desses dois programas. Diversos estudos apontam os significativos avanços em termos de políticas públicas para esse segmento e abrem espaços para que novas pesquisas sinalizem os efeitos dos programas de compra institucional no contexto local (GRISA, 2012; BONNAL e MALUF, 2009; GRISA e SCHNEIDER, 2014; PEIXINHO, 2013; JANUÁRIO, 2013; TRICHES, 2010). Assim, compreender as implicações das políticas governamentais para esse setor passa a ser uma importante forma de conhecer os efeitos de tais ações em nível local, junto aos atores sociais envolvidos. O estudo empírico dos atores e de suas organizações torna-se absolutamente crucial para compreender as microrrealidades. A partir desta perspectiva, este trabalho procura analisar os efeitos gerados na agricultura familiar a partir da operacionalização dos programas PAA e PNAE no contexto local. Para delimitar o recorte da pesquisa procurou-se estudar o caso do município mineiro de Espera Feliz.

Para desenvolver a pesquisa, foram mapeados trabalhos que discutem os efeitos do PAA ou PNAE, dentre os quais se destacam os estudos sobre o PAA de: Delgado et al. (2005), Mattei (2007b), Chmielewska, Souza e Lourete (2010); e sobre o PNAE: Abreu (2014), Ciro e Freitas (2013), Paiva, Freitas e Santos (2012). Todavia, os estudos acadêmicos existentes sobre o PAA e PNAE estão centrados, majoritariamente, nas análises de impacto individual de cada programa. Existem ainda alguns estudos que abordam os dois programas através de ensaios teóricos; porém, a análise empírica e ampla sobre os efeitos conjuntos dessas ações para a realidade local ainda é incipiente. Outro destaque é que existem poucas orientações de como promover o diálogo entre as duas políticas, embora ambas sejam realizadas com protocolos e competências necessárias para a correta implementação e operacionalização em níveis locais. Considerando-se essa lacuna, este estudo almeja contribuir para a análise conjunta dos programas.

A escolha de Espera Feliz justificou-se por apresentar características bem próximas às da maioria dos municípios brasileiros, mineiros e da Zona da Mata de MG, ou seja, com até 50 mil habitantes e elevada 
concentração de pequenas propriedades (menos de 100 ha). Especificamente na mesorregião Zona da Mata, dos 142 municípios, $134(94,4 \%)$ têm até 50 mil habitantes (IBGE, 2010) e $82 \%$ dos 86.437 estabelecimentos rurais existentes são da agricultura familiar (IBGE, 2006). Dentre os 134 pequenos municípios, Espera Feliz é o que tem o maior número de Documento de Aptidão ao Pronaf (DAP) $)^{5}$ registrado no Ministério do Desenvolvimento Agrário (MDA), apresentando 1.679 declarações ativas, ou seja, é o município que tem o maior número de agricultores familiares registrados e aptos a acessarem as políticas públicas para o setor (MDA, 2014). Associado a isso, dos 22.856 residentes no município, 2.425 encontravam-se em situação de extrema pobreza ${ }^{6}$, em que $1.833(75,6 \%)$ viviam no meio rural, número superior ao da média da mesorregião de $52,2 \%$ (IBGE, 2010).

Logo, o presente trabalho objetiva compreender, por meio de categorias pré-definidas (econômico, social, ambiental e segurança alimentar), os efeitos da execução dos programas PAA e PNAE para os agricultores familiares que forneceram alimentos entre $2013 \mathrm{e}$ 2014 em Espera Feliz.

Para desenvolver as análises propostas, o artigo foi dividido em cinco partes, além desta introdução. A seção 1 busca delimitar e caracterizar, em termos analíticos, o reconhecimento do Estado da categoria sociopolítica agricultura familiar. Posteriormente será apresentado o processo de compras institucionais de alimentos no Brasil, via políticas públicas, em que estão expostos o PAA e o PNAE. Na seção 3 serão apresentados os procedimentos metodológicos utilizados para a condução desta pesquisa científica, revelando as opções adotadas quanto ao tipo de pesquisa, universo do estudo, coleta dos dados e organização e análise dos dados. Na sequência, serão apresentados os resultados e discussões, em que são abordadas as implicações socioeconômicas e ambientais da compra governamental de alimentos a partir da visão dos agricultores beneficiários. As considerações finais serão pontuadas na última seção.

5. O Documento de Aptidão ao Pronaf (DAP) é o instrumento que identifica os Agricultores Familiares e/ou suas formas associativas organizadas em pessoa jurídica, e confere a estes o direito a acessar políticas públicas, como o Pronaf, PAA, PNAE, Habitação Rural, Biodiesel, entre outras (BRASIL, 2014c).

6. Considera-se em extrema pobreza aquela população com renda familiar per capita mensal de até R\$ 70,00 (BRASIL, Decreto 7.492/2011).

\section{Políticas Públicas e agricultura familiar no Brasil}

No Brasil, os pequenos agricultores foram colocados durante muito tempo à margem das agendas governamentais, enquanto a agricultura empresarial, que esteve voltada à produção de commodities, recebeu elevados incentivos financeiros do Estado (ALTAFIN, 2007). Segundo Wanderley (1999, p. 37), "esse setor foi historicamente bloqueado, impossibilitado de desenvolver-se enquanto agente importante de produção". Para a autora, os agricultores familiares, até então denominados pequenos agricultores, tiveram o caminho dificultado para desenvolver as potencialidades enquanto importante categoria social no cenário socioeconômico brasileiro.

Foi no contexto da década de 1980 que os grupos de pequenos agricultores organizados em diferentes formas e orientações políticas reivindicaram ao Estado brasileiro políticas públicas que os incluíssem na agenda de prioridades dos governos (SCHNEIDER, 2010). Os movimentos sociais rurais intensificaram as exigências na luta para criação de políticas públicas voltadas às necessidades dos pequenos agricultores, como: crédito, garantia de preço e acesso ao mercado. Nesse período, "as políticas públicas e discussões teóricas sobre desenvolvimento rural se restabeleceram em bases analíticas diferentes daquelas da década de 1970" (SCHNEIDER, 2010, p. 512).

As políticas voltadas exclusivamente para agricultura familiar ganham impulso no Brasil no decorrer da década de 1990. A delimitação da agricultura familiar acontece num processo conhecido como focalização da política pública (Targeted Public Policy), onde o Estado reconhece a necessidade de separar os focos de intervenção em uma realidade, vista antes como única.

Assim, em 1995 foi criado, por meio da resolução do Banco Central do Brasil n. 2.191, o Pronaf ${ }^{7}$, sendo instituído posteriormente em 1996, cujo objetivo foi fornecer crédito subsidiado para custeio e investimento para a agricultura familiar (BRASIL, 1995, 1996b). Com o Pronaf, as políticas voltadas para a agricultura familiar experimentaram crescimento expressivo, ampliando seu escopo e escala (SANTOS, 2011). Nesse momento ocorreram também importantes con-

7. A Resolução n. 2.191, de 24 de agosto de 1995, foi revogada pela Resolução n. 2.310, de 29/08/1996. 
quistas institucionais, principalmente a partir da criação do Ministério do Desenvolvimento Agrário (MDA), em 1999. No governo Lula (2003-2010) foram criadas várias políticas sociais articuladas com outros ministérios, ganhando destaque o PAA, a reformulação do PNAE, Programa Mais Alimentos, Programa Minha Casa Minha Vida Rural, Luz para Todos, Bolsa Verde e outras ações de desenvolvimento rural que buscam o desenvolvimento sustentável da agricultura familiar. A operacionalização destes programas exigiu por parte do estado brasileiro uma definição normativa da categoria Agricultor Familiar a fim de eleger os beneficiários. Assim, foi aprovado, em 2006, a Lei n. 11.326 que passou a considerar agricultor familiar e empreendedor familiar rural aquele que pratica atividades no meio rural, atendendo simultaneamente aos seguintes requisitos: I - não detenha, a qualquer título, área maior do que quatro módulos fiscais; II - utilize predominantemente mão de obra da própria família nas atividades econômicas do seu estabelecimento ou empreendimento; III - tenha renda familiar predominantemente originada de atividades econômicas vinculadas ao próprio estabelecimento ou empreendimento; IV - dirija seu estabelecimento ou empreendimento com a família (BRASIL, 2006).

Assim, a partir de novos programas e caracterização da agricultura o Estado passou a atuar em diversas frentes que historicamente foram pauta de reivindicações dos movimentos sociais rurais, como crédito, seguro, mercado, infraestrutura, alimentação, habitação, entre outros temas de interesse da agricultura familiar.

\section{O Programa de Aquisição de Alimentos (PAA)}

Com a ideia de combater a fome e a pobreza, o PAA foi instituído em 2003 como uma das ações estratégicas do Programa Fome Zero. Criado como um instrumento de acesso aos alimentos, viabilizou a articulação entre produção e consumo adequado à realidade local e contribuiu para o fortalecimento da agricultura familiar e para a geração de ocupação e renda (PAGANINI, 2010).

O PAA é um programa que beneficia não apenas as entidades socioassistenciais e agricultores familiares, mas toda uma rede de relações estabelecidas entre a produção e o consumo. O PAA é muito importante para a economia local, haja vista que, de um lado, busca fomentar o desenvolvimento da agricultura familiar, com o incentivo à participação de mulheres no mercado e cultivo de alimentos orgânicos, bem como da sociobiodiversidade; e de outro lado, busca efetivar a segurança alimentar de parte da população brasileira, que ainda vive em situação de risco nutricional.

Atualmente, o PAA é executado com recursos dos Ministérios do Desenvolvimento Agrário (MDA) e do Desenvolvimento Social e Combate à Fome (MDS), por meio da Companhia Nacional de Abastecimento (Conab), em parceria com estados e municípios. No desenho do programa, estado, sociedade e mercado possuem papéis importantes na produção, distribuição e consumo. Diante da complexidade das demandas institucionais e também da diversidade de alimentos produzidos, o programa foi planejado com seis modalidades.

\section{O Programa Nacional de Alimentação Escolar (PNAE)}

$\mathrm{O}$ que se conhece atualmente como Programa Nacional de Alimentação Escolar (PNAE) é uma política pública criada em 1955 com nome inicial de Campanha Nacional de Merenda Escolar (CNME). Foi por meio do Decreto n. 37.106/1955 que o Ministério da Educação instituiu o CNME, inspirado no NSLP (National School Lunch Program), desenvolvido nos Estados Unidos desde 1946. A ação deu bases para a primeira iniciativa nacional de direito à alimentação escolar a estudantes de escolas públicas.

As experiências na gestão e operacionalização da alimentação escolar no Brasil passaram por diversos estágios, abarcando características distintas de centralização e descentralização, focalização e universalização, financiamento público e privado.

No governo Lula (2003-2010), impulsionado pela estratégia de combate à pobreza e à fome, o PNAE ganha novos contornos com a promulgação da Lei n. 11.947, em 2009, que estende a alimentação escolar para toda a rede pública de Educação Básica e de Jovens e Adultos, que também recomenda que o mínimo de 30\% do repasse do FNDE sejam investidos na aquisição de produtos da agricultura familiar. A nova lei serviu não só como uma política de melhoria 
na qualidade da alimentação dos estudantes, mas também teve influências no cenário econômico de diversas localidades. Para Reinach, Corá e Bonduki (2012), essa nova lei pode ser caracterizada pela hiperdescentralização, em que, além de a compra acontecer em nível local, também é priorizado o acesso ao mercado aos agricultores familiares.

A exigência da compra da agricultura familiar foi inspirada na experiência acumulada do PAA de 2003, bem como nos efeitos para agricultura familiar e segurança alimentar. O programa completou 60 anos em 2015, mostrando que as diversas reformulações ocorridas tiveram intuito de promover melhorias na gestão e cobertura, como também a conexão das políticas de segurança alimentar e de desenvolvimento agrário. Pelo desenho e abrangência, o programa brasileiro é referência mundial para a ONU e muitos países do mundo no quesito de boas práticas de políticas públicas para o desenvolvimento.

\section{Convergências e distinções entre o PAA e o PNAE}

Os programas PAA e PNAE têm trajetórias diferentes, principalmente por terem sido formulados em momentos distintos. Porém, têm como base comum a compra institucional local de produtos da agricultura familiar para ações de segurança alimentar e nutricional. Para Ávila, Caldas e Assad (2013, p. 77), "as trajetórias de ambas as políticas demonstram que há significativos avanços na integração entre elas".

A assertiva dos autores supracitados se justifica pelo fato de que o PAA foi o primeiro programa do governo federal brasileiro a focar a inserção da agricultura familiar no mercado institucional em escala nacional. Até então, os produtos da agricultura familiar tinham como principal mercado os arranjos de comercialização informal, feiras livres e venda para atravessadores. Dessa forma, o programa representou uma oportunidade de se estruturar para atender outros mercados. Por sua vez, o PNAE garantiu a inserção da agricultura familiar em escala nacional no mercado institucional com a Lei n. 11.947/09, e tem orçamento garantido via recursos do FNDE, que independe do desejo do governante. Diante disso, o PNAE faz a conexão da segurança alimentar para estudantes e também possibilita a geração de trabalho e renda no meio rural.
O PNAE cria demanda constante de compra para o agricultor produzir durante 10 meses por ano (200 dias letivos), enquanto o PAA depende de aprovação de projetos, em que nem todos os municípios são atendidos; quando o são, a vigência é de 12 meses (365 dias ao ano).

O PNAE é um programa ligado à educação e é essencialmente voltado para instituições de Ensino Básico, o que, em prática, exclui todas as outras entidades socioassistenciais e equipamentos públicos de alimentação que não têm como usuários os estudantes. Por sua vez, o PAA é mais abrangente ${ }^{8}$, pois fornece alimentos a entidades socioassistenciais e também a escolas públicas e privadas, que comprovadamente atendam pessoas em situação de vulnerabilidade alimentar.

O PAA tem características mais centralizadas, pois os projetos elaborados pelas organizações e prefeituras dependem de aprovação das superintendências estaduais da Conab, e posteriormente do MDA, em Brasília, o que pode delongar o processo de análise e a aprovação e liberação do recurso. O PNAE tem características mais descentralizadas, em que estados e municípios recebem os recursos fundo a fundo para a compra de alimentos. No PNAE existem 4 tipos de gestão da alimentação escolar: centralizada, descentralizada, semidescentralizada e terceirizada ${ }^{9}$.

Quanto aos limites, o PAA possui vários tetos-limites de venda por produtor, seja por semestre ou por ano. A modalidade mais utilizada é a compra com doação simultânea (CDS), com limite anual de R\$

8. Segundo relatório executivo do MDA de $2013,44,76 \%$ das alimentos do PAA são destinados a creche, pré-escolas e escolas, seguidos por $26,38 \%$ associações beneficentes e comunitárias, $8,23 \%$ a instituições religiosas e de mulheres, e $20,63 \%$ a outros tipos de entidades socioassistenciais (MDA, 2013).

9. Na gestão centralizada, os recursos repassados pelo FNDE são diretamente na conta específica da entidade executora que compra os alimentos e os distribuem para as escolas da sua rede de ensino. Na semidescentralizada o processo é o mesmo, porém, pode-se decidir entre duas maneiras de executar: ou compra e distribui os alimentos não perecíveis nas escolas e repassa parte dos recursos às escolas para a compra dos perecíveis; ou a EE compra e distribui os alimentos perecíveis e não perecíveis nas escolas da zona rural e repassa o recurso financeiro para as escolas da zona urbana. A gestão descentralizada ou escolarização é a gestão em que a entidade executora recebe os recursos do FNDE e os repassa às escolas que, por sua vez, comprarão os gêneros alimentícios a serem utilizados na preparação do cardápio da alimentação escolar. Por fim, a tterceirização possibilita às entidades executoras a contratação de empresa para o fornecimento das refeições às escolas de sua rede. 
$6.500,00^{10}$ por agricultor/ano. O PNAE, por sua vez, tem um único limite, iniciado com $\mathrm{R} \$ 8.000,00$ - atualmente está em R\$20.000,00 por agricultor/ano.

Quanto aos tipos de alimentos que são adquiridos, o PAA não impõe restrições iniciais: o único limitante é que os produtos estejam discrimados previamente na proposta aprovada junto aos órgão gestores do programa. No PNAE, são adquiridos alimentos enquadrados no cardápio elaborado pelo(a) nutricionista do municipio/estado. Assim, no PAA existe certa flexibilidade quanto ao que produzir, enquanto o PNAE é mais complexo pois o tipo e a periodicidade de entrega são elaborados pelos reponsáveis governamentais.

Em relação à aquisição de alimentos, no PAA é determinado que $100 \%$ seja da agricultura familiar, ao passo que, no PNAE, o mínimo deve ser 30\%, variando de município para município o montate financeiro destinado para compra de produtos da agricultura familiar.

Em comum, ambos os programas têm como objetivo apoiar e fortalecer, em níveis local e regional, capacidades sociais de promoção do desenvolvimento, nos quais as próprias organizações dos agricultores familiares protagonizam as iniciativas sustentáveis, conforme Figura 1:

Figura 1. Ações sustentáveis do PAA e PNAE

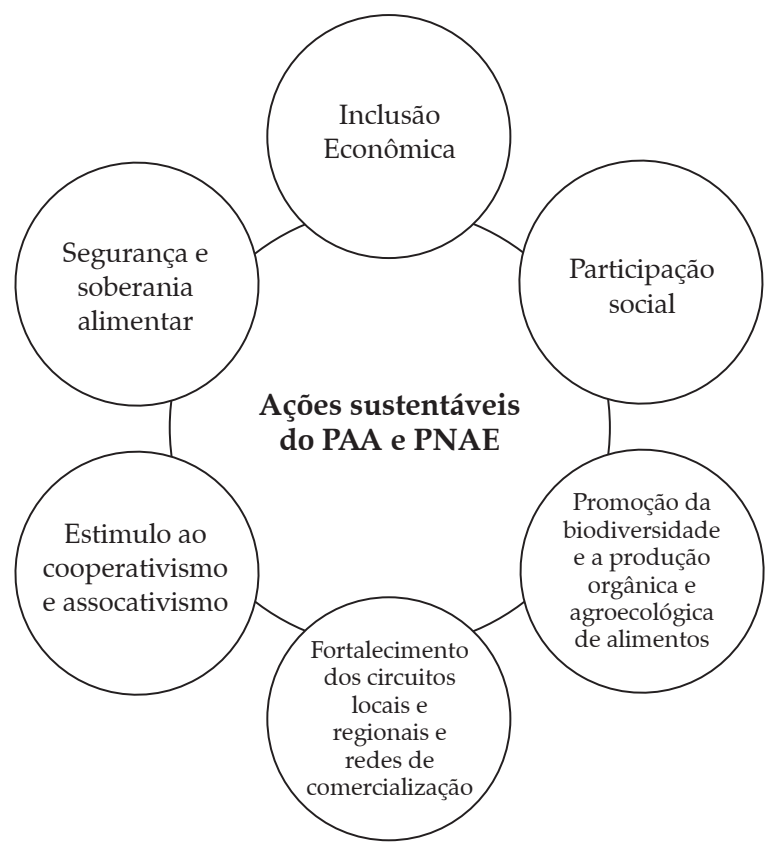

Fonte: Elaboração própria.

10. Existe a possibilidade de participar simultaneamente de mais de uma modalidade.
Os dois programas são parte integrante da estratégia de segurança nutricional e alimentar do Brasil, e se cruzam com outras políticas sociais como educação e saúde, bem como com objetivos mais vastos de redução da pobreza e desigualdade (ONU, 2013).

Os recursos disponíveis anualmente para PAA e PNAE, combinados, representam demanda potencial de R\$ 2,2 bilhões anuais, destinados a compras de produtos de agricultores familiares brasileiros, o que gera grande impacto sobre a produção e a renda desses agricultores (BRASIL, 2014a; ONU, 2014).

Segundo Dowbor et al. (2006), esses e outros programas possuem capacidades de contribuir no desenvolvimento em regiões menos desenvolvidas, oportunizando, assim, a dinamização de pequenos investimentos e dos fluxos econômicos em nível local. Portanto, o PAA e PNAE assumem importância vital para as políticas de segurança alimentar e agricultura familiar no Brasil, gerando efeitos sinérgicos para o desenvolvimento local.

\section{Procedimentos metodológicos}

Para o alcance dos objetivos propostos por esta pesquisa, optou-se por um estudo com abordagem qualiquantitativa, com predominância qualitativa. Os dados quantitativos foram utilizados, principalmente, na complementação e no reforço dos resultados coletados qualitativamente durante as entrevistas, contribuindo para endossar as interpretações. Quanto à natureza, esta pesquisa classifica-se como descritiva, pois tem o objetivo de ilustrar uma situação e os aspectos nela envolvidos, realizando-se uma análise contextual do fenômeno social (GODOI, BANDEIRA DE MELLO e SILVA, 2006).

Sob orientação semelhante, o universo ou a população de estudo é definido por Richardson (2010) como um conjunto de elementos característicos relacionados com o objetivo do pesquisador. Assim, o universo dos pesquisados foi constituído por representantes de entidades de apoio (Emater, Secretarias municipais de educação e a Cooperativa da Agricultura Familiar Solidária de Espera Feliz - Coofeliz) e todos os beneficiários fornecedores de alimentos para o PAA e/ou PNAE no município de Espera Feliz, situado no leste da Zona da Mata Mineira.

Quanto à seleção dos agricultores entrevistados, foi definida a entrevista junto a todos aqueles que 
forneciam alimentos para o PAA e/ou PNAE, ou seja, foi realizado um censo junto a 61 famílias de agricultores associados na Coofeliz que forneceram para os dois programas em 2013 e/ou 2014.

Foram utilizados dados secundários e primários, a partir da análise de pesquisa documental e também dados primários com a utilização da técnica observação participante, bem como de entrevistas semiestruturadas. A pesquisa documental foi realizada a partir dos cadastros dos agricultores na cooperativa, plano de negócios, documentos contábeis, prestação de contas dos gastos nos programas, orientações, cartilhas, na legislação e documentos publicados pelo governo federal, já que Alves-Mazzotti e Gewandsznajder (1999, p. 169) consideram documento "qualquer registro escrito que possa ser utilizado como fonte de informação". A observação participante aconteceu nos dias de entrega dos alimentos pelos agricultores na cooperativa $^{11}$, reuniões da diretoria e também a visita in loco para realizar as entrevistas e conhecer a realidade na qual os agricultores estão inseridos. As informações observadas durante as visitas aos diversos espaços foram registradas em um diário de campo. As entrevistas semiestruturadas foram realizadas presencialmente, cujos sujeitos de pesquisa foram, principalmente, os cooperados fornecedores para o PAA e PNAE da Coofeliz e também os representantes de entidades de apoio. Os roteiros foram estruturados a partir da categorização de cada um dos atores envolvidos no processo, quais sejam: agricultores, diretores da cooperativa, as entidades de apoio e a nutricionista do município.

Para a interpretação dos dados foi utilizada a técnica de análise de conteúdo. Bardin (2011) afirma que esta técnica é utilizada, particularmente, em pesquisas do tipo qualitativo. $\mathrm{O}$ mesmo autor ressalta que esse método consiste em desmembrar o texto em unidades, cujo objetivo é fornecer uma representação simplificada dos dados brutos. A escolha de categorias de efeito dos programas foi feita a partir do conceito da multifuncionalidade da agricultura familiar, desenvolvida principalmente por Cazella, Bonnal e Maluf (2009), e também de estudos já realizados sobre os impactos do mercado institucional de alimentos no Brasil. Assim, foram consideradas quatro categorias

11. Todas as segundas-feiras, no período da manhã, os alimentos são entregues e separados na Coofeliz. (econômica, social, ambiental, segurança alimentar), com desdobramento em outras 11 subcategorias indicativas sobre o tema proposto. A seguir são apresentadas as categorias e os interesses sobre elas, indicando algumas questões que foram exploradas: i) Dimensão Econômica: o quão significativas têm sido as ações do mercado institucional de alimentos (PAA e PNAE) para a geração de trabalho e emprego, renda, produção, diversificação da produção e acesso a novos mercados? ii) Dimensão Social: quais as implicações reais dos programas para o fortalecimento da organização social, envolvimento familiar e as relações institucionais? iii) Dimensão ambiental: os programas têm induzido o modo de produção dos agricultores no sentido de torná-lo mais sustentável e agroecológico? e iv) Segurança alimentar: quais os efeitos para o autoconsumo, qualidade dos produtos?

\section{Resultados e discussão: efeitos da compra institucional de alimentos para a agricultura familiar em Espera Feliz (MG)}

\subsection{Categoria econômica}

Quanto à categoria econômica, salienta-se que um dos objetivos dos programas é incentivar a agricultura familiar, promovendo a sua inclusão econômica via compra institucional. Para compreender quais as implicações econômicas que o PAA e PNAE estão proporcionando juntos aos agricultores familiares de Espera Feliz, foram analisadas duas subcategorias: 1) produção e mercado e 2) trabalho e renda.

\subsubsection{Produção e mercado}

A produção agropecuária brasileira vem crescendo de forma expressiva em todos os níveis, desde a década de 1970. Grisa e Schneider (2014) destacaram que o acesso a mercado é um dos maiores gargalos da agricultura familiar e limita o aumento da produção pelas famílias pela limitada fonte de recursos acessados. Logo, ao não terem condições de concorrerem com grandes produtores os agricultores familiares se veem com limitadas condições de geração de renda. Esta é uma das justificativas de criação dos programas de compra institucional e da necessidade de avaliação 
do impacto desses programas na efetiva melhora destas condições comerciais.

Em Espera Feliz, os agricultores são enfáticos quando afirmam que o escoamento da produção é um dos motivos de entrada nos dois programas:

Eu decidi porque é melhor, a gente vai a um lugar só para entregar, geralmente nas segundas-feiras, aí fica melhor para a gente, pois não precisamos ficar andando, entregando ali e aqui (Agricultor 03).

Primeiro porque a gente já produzia e a gente viu que era mais um mercado. Porque, na realidade, para alguns produtos a gente nem tinha mercado. Aí, com isso, abriu as portas para comercializar (Agricultor 26).

Eu vi que compensava, porque realmente lá é um lugar que você tem para entregar, é um lugar certo (Agricultor 47).

A gente agora tinha nas mãos um mercado garantido. $\mathrm{O}$ melhor era saber que eu posso entregar até minha taioba ou outras coisas que até perdiam aqui no quintal. Agora pode vender de tudo, o preço é bom e a venda é garantida (Agricultor 53).

Conforme os depoimentos acima, a percepção dos agricultores referente à satisfação de participação no programa está, entre alguns motivos, condicionada ao fenômeno da abertura para o mercado formal e da valorização dos produtos da agricultura familiar local. As dificuldades encontradas por esses agricultores em acessarem outros mercados devido às exigências legais e à padronização dos produtos foram notadas como entraves superados pelos programas de compra institucional. Os agricultores tinham nas feiras locais e vendas de "porta em porta" as principais fontes de escoamento. Porém, como relata o agricultor 20, "as vezes tinha que voltar para casa sem vender tudo, e perdia produto. Mas era melhor que nada".

Foi possível observar, pelos relatos e dados coletados em campo, que a implementação desses novos programas no município possibilitou a ampliação da área de produção, pois quando há mercado garantido, o produtor sente confiança para produzir mais e, consequentemente, diminui possíveis prejuízos financei- ros e de trabalho em decorrência da instabilidade que outros mercados poderiam proporcionar.

O aumento da produção é verificado na Tabela 1, quando perguntado se houve aumento a partir das entradas no mercado institucional.

Tabela 1. Produção de alimentos a partir da inserção no PAA e PNAE

\begin{tabular}{lcc}
\hline \multicolumn{1}{c}{ Produção } & Frequência (n) & Frequência (\%) \\
\hline Aumentou & 51 & 83,6 \\
Manteve & 9 & 14,8 \\
Diminuiu & 1 & 1,6 \\
Total & $\mathbf{6 1}$ & $\mathbf{1 0 0}$ \\
\hline
\end{tabular}

Fonte: Dados da pesquisa.

Ainda sobre o aumento da produção, verifica-se que a estabilidade de pedido e o pagamento garantido foram motivadores para que os agricultores intensificassem o plantio, conforme depoimentos a seguir.

Passei a produzir mais. [...] Olha, a mandioca aqui eu só tinha mesmo como meu uso pessoal. Aumentei muito o plantio dela. Inhame eu não plantava; eu passei a plantar depois que dava pra vender tranquilo. A batata-doce eu não plantava; passei a plantar. Eu plantava a horta aqui e punha na bicicleta eu e meu menino à noite, nós vendíamos à noite na rua. Aí foi até eu entrar no projeto, eu entrei no PAA e PNAE, aí eu aumentei (Agricultor 14).

Sem dúvida que aumentou. Hoje eu tenho três irrigações, tenho uma a diesel, uma a gasolina e uma a energia elétrica. Eu gastei, investi muito. Tem coisa que nós nem nunca tínhamos comido, couve-flor principalmente, nós nunca tínhamos comido aquilo, aí plantamos (Agricultor 40).

Verifica-se que muitos agricultores começaram a investir em plantios que nunca tinham produzido. $\mathrm{O}$ pedido regular de alimentos oferece maior segurança para investirem em cultivos que demandam maiores recursos físicos e financeiros. O elemento de garantia de entrega dos alimentos é absolutamente importante para estimular os agricultores, dado as condições em que produzem, ou seja, com pouca escala de produção e produtos perecíveis - garantia de suma importância para a produção familiar. Situação similar foi identificada em vários trabalhos assim como: Doretto 
e Michellon (2007); Bortolatto (2009); Chmielewska, Souza, Lourete (2010).

Os depoimentos indicam que há entre os produtores a manifestação de interesse em diversificar a produção, inclusive com produtos que normalmente não produzem para comercialização - caso específico de alimentos que eram produzidos só para o consumo próprio. Este processo de incentivo a novos cultivares culmina em maior diversificação da produção. Para Wanderley (1999), o empenho para diversificação vai além da ampliação do rol de produtos comercializáveis, ao evidenciar a garantia do autoconsumo familiar e a proteção da agrobiodiversidade local e impactar na segurança alimentar da família rural.

Analisando a opinião dos agricultores cooperados em relação às possíveis alternativas para a diversificação agrícola, verificou-se que existe uma convergência de opiniões entre os entrevistados sobre o plantio diversificado e consorciado com café, em que os melhores cultivos intercalados são de culturas como banana, feijão, abóbora - que são plantadas no mesmo espaço geográfico e que não atrapalham a produção da atividade principal. Também se percebeu que, em geral, nas partes mais altas das propriedades é cultivado o café; e nas partes baixas, outros tipos, como hortaliças (DIÁRIO DE CAMPO, 2014).

De maneira geral, a diversificação agrícola impulsionada pelo mercado institucional foi uma alternativa viável que os agricultores familiares encontraram para enfrentar os riscos da monocultura cafeeira, uma vez que esse monocultivo era, até pouco tempo, a única fonte de renda das famílias, que sofriam com as oscilações de preços e as oportunidades comerciais. Além disso, percebe-se que a produção agrícola já não é mais a única e, em alguns casos, nem a principal fonte de renda das famílias, pois alguns agricultores produzem alimentos beneficiados como doces, queijos, biscoitos, assim como alguns desempenham funções também na área urbana.

\subsection{Categoria social}

$\mathrm{Na}$ segunda categoria, as análises foram focadas nos efeitos dos programas sobre as relações político-sociais dos agricultores, em que as subcategorias escolhidas foram: organização social, ampliação das relações institucionais e envolvimento familiar. Esta categoria nos revela que os programas geram resulta- dos que vão muito além dos 30\% determinado pela Lei n. 11.947 de 2009 e do ato de aquisição dos alimentos. O processo desencadeado para que a compra pública ocorra necessita da devida interação entre diferentes atores sociais, caracterizando esse mercado institucional como uma construção social.

\subsubsection{Organização social}

A Coofeliz opera como única organização coletiva que operacionaliza o PAA e o PNAE no município. A cooperativa, na percepção dos agricultores, tem papel importante para a comercialização dos produtos via mercado institucional, conforme relatos abaixo:

[...] acho que, se não fosse a cooperativa, nós tava n'água, você pode fazer até via grupo comunitário, associação comunitária, aí esbarra na questão das notas fiscais, e a cooperativa não, tem condição de fazer tudo melhor, tem muito agricultores que não são, às vezes organizado, pela condição dele, aí se ele se ligar a cooperativa, ajuda ele a organizar o lado dele também, então é um monte de coisas que envolve uma cooperativa (Agricultor 04).

A fala do agricultor acima demonstra a confiança com a organização e reforça importância na operacionalização do programa. Segundo Freitas e Freitas (2013, p. 178), as mudanças na agricultura familiar ocorrem ligadas às novas "formas de governança do desenvolvimento rural no Brasil, induzem as organizações de agricultores familiares a assumirem novos papéis". Assim, a Coofeliz foi induzida a realizar todo o trabalho de organização e planejamento para acessar o mercado institucional e outros mercados. Com a introdução do PAA e do PNAE, a Coofeliz precisou se adequar às exigências legais e estabelecer nítida relação com a prefeitura para negociar o processo de aquisição de alimentos.

O papel da cooperativa na logística também é apontado como importante na operacionalização comercial do PAA no município e no atendimento às normas legais preconizadas para a comercialização dos produtos, conforme relata o agricultor familiar a seguir:

A cooperativa é importante porque ela trabalha com toda a papelada e burocracia, banco... 
Eles também ficam na cidade, aí fica tudo mais fácil de resolver as coisas com a prefeitura e as escolas. [...] eles também têm um caminhãozinho que ajuda muito, pois se cada agricultor tivesse que entregar seria mais complicado (Agricultor 02).

A importância da cooperativa também é notada pela facilidade no pagamento do que é produzido, pois o agricultor entrega o alimento na cooperativa e, logo em seguida, recebe o vale solidário ${ }^{12}$, que pode ser trocado em vários estabelecimentos no município. Essa é uma vantagem competitiva quanto ao recebimento das vendas, em comparação a outros canais de comercialização, pois a existência do "fiado"13 bainda é comum no município.

Entre 2006 e 2014, período que compreende o início do acesso da cooperativa no mercado institucional, o número de cooperados aumentou consideravelmente, saltando de 37 pra 105, respectivamente. Esses números sugerem que o PAA e PNAE contribuíram significativamente para o fortalecimento da cooperativa. Em 2006, apenas 22 agricultores forneciam alimentos para o PAA, ao passo que, em 2012, esse número aumentou para 61, destacando a inclusão do PNAE como mais uma oportunidade a partir de 2009. Muitos dos outros 61 agricultores que não fornecem atualmente já participaram em outros projetos anteriores, mas, por motivos ${ }^{14}$ diversos, não estão entregando. Quando perguntados se a inserção na cooperativa se deu devido ao PAA e PNAE, 49 (80,3\%) agricultores responderam que sim, visto que as vendas anteriores da cooperativa ao mercado institucional eram limitadas e apenas para um pequeno grupo de produtores.

Conforme pode ser observado nos dados e nas declarações dos agricultores familiares, a cooperativa é o ator central no processo de implementação destas políticas públicas ao mobilizar os agricultores e organizar o processo comercial e produtivo. Os dados indicaram que a organização foi fortalecida a partir do

12. O Vale Solidário é uma espécie de moeda social criada para contornar o problema da demora do pagamento. $\mathrm{O}$ pagamento pelos alimentos comprados via estes programas demoram entre 30 e 60 dias para acontecer.

13. Compra a prazo, realizada por pessoas com base na relação de confiança - que tem um risco de inadimplência alto.

14. Entre os motivos estão o preço pago, pouca demanda, descontinuidade de um projeto para o outro. mercado institucional, aumentando o número de associados e ganhando mais autonomia financeira para executar suas atividades.

\subsubsection{Envolvimento familiar na produção}

A agricultura familiar se caracteriza pelo emprego da mão de obra familiar nas atividades produtivas. $\mathrm{O}$ envolvimento familiar se caracteriza como elemento preponderante na garantia da reprodução social. Os estudos de Carneiro (2001), Weisheimer (2004) Brumer e Spanevello (2008) referentes à reprodução social da agricultura familiar mostram que filhos de agricultores familiares já apresentam a recusa em permanecer na ocupação agrícola e no meio rural. A desistência dos filhos pela ocupação agrícola está baseada em diferentes razões que vão desde a questão da renda, da penosidade do trabalho agrícola e da desvalorização da ocupação. Por isso, acentuar a valorização do trabalho familiar e da agricultura familiar pode impactar positivamente na reprodução social da agricultura familiar.

Em Espera Feliz foi enfatizado o papel importante da família na produção dos alimentos para o mercado institucional. Os programas têm estimulado a reorganização funcional entre os membros familiares, proporcionando autonomia pessoal e financeira dos jovens e mulheres envolvidos. Os trabalhos coletivos, com a ajuda da família, são momentos comuns entre os agricultores familiares entrevistados. Cada um ajuda da maneira que pode, sempre com o objetivo de atender, no prazo estipulado, a entrega dos produtos.

Em geral, o trabalho da mulher e do jovem varia de acordo com o que é produzido e com a etapa do ciclo agrícola, contribuindo principalmente nos trabalhos menos pesados e próximos da casa. Os relatos coletados em campo indicaram o envolvimento de todos os membros da família nas atividades da produção para o mercado institucional, além de criar alternativas de renda monetária e elevação da autoestima.

O envolvimento de mulheres é destaque no município, pois existem 124 mulheres nas famílias dos agricultores, sendo que 26 são sócias da cooperativa. O relato, exposto a seguir, retrata a importância das mulheres na contribuição para a produção e comercialização dos produtos para o programa:

Os programas ajudam a melhorar a nossa renda e autoestima. [...] Nos sentimos útil [...]. 
Então participamos na parte do que se planta, do que se colhe, mas também no lucro que entra na propriedade (Agricultora 06).

Agora a mulher e o jovem têm vez [...] Antes eu não podia ajudar na panha de café, pois era um trabalho muito pesado. Agora com a horta eu dou conta. Meu filho também depois da aula sempre ajuda um pouco (Agricultora 59).

No depoimento das entrevistadas é destacado o papel dos programas para a elevação da autoestima das mulheres. Isso acontece porque os homens se concentram mais na produção do café, ficando a cargo da mulher o empenho na produção das hortaliças e legumes, produtos mais vendidos. Como relatou a Agricultora 59, "nós somos mais valorizadas porque hoje fazemos mais parte desse processo".

No município existe um grupo de mulheres da agricultura familiar vinculado ao STR, que desenvolve várias atividades relacionadas ao artesanato, a cursos de aprendizado rural e a demais atividades produtivas. O que se aprende nas reuniões do grupo acaba se refletindo nas práticas produtivas do PAA e PNAE local, pois nas reuniões são discutidas práticas para estimular a autonomia da mulher. Os resultados encontrados em Espera Feliz corroboram os casos pesquisados por Siliprandi e Cintrão (2013). Nos estudos realizados por essas pesquisadoras em Barbacena (MG), Pelotas (RS), São Luís (MA), e Itaperuçu Mirim (MA), foi percebido que, onde existiam movimentos organizados de mulheres rurais, mesmo que esses não priorizassem as questões produtivas, a participação formal dessas no PAA era maior, mostrando que um ambiente favorável à discussão dos direitos das mulheres tendia a levar a seu maior reconhecimento como importantes agentes econômicos.

Os jovens também têm papel importante na produção dos alimentos, pois conciliam horários entre estudo ou trabalho externo com cuidados com a lavoura da própria família. O trabalho também é visto como um aprendizado das práticas agrícolas entre as famílias que têm jovens ajudando na produção para o mercado institucional. A participação e o envolvimento do jovem são benéficos, pois incentivam e valorizam o aprendizado do trabalho no campo, dificultando, assim, a migração, o êxodo rural e o esvaziamento do campo, apontado por Abramovay e Camarano (1998) como uma das maiores ameaças para o desenvolvimento rural.

\subsection{Categoria ambiental}

A agricultura brasileira é pautada em maior ou menor escala por alguns métodos de produção. Entre os vários tipos, há aqueles que utilizam máquinas e equipamentos modernos, sementes geneticamente modificadas, defensivos e fertilizantes químicos, praticada principalmente pela agricultura empresarial (LEITE e MEDEIROS, 2012). Por outro lado, há os que utilizam recursos da própria natureza para sua produção, incorporando princípios ecológicos de preservação da natureza (PETERSEN, 2012). Esse último modo de produção é conhecido como agroecológico ou produção orgânica, em que se defende que é possível produzir alimentos de qualidade superando a dependência por insumos químicos e práticas prejudiciais ao meio ambiente.

Em Espera Feliz as práticas de produção orgânica ou livre de agrotóxico são motivadas principalmente por questões sociais, ambientais e de saúde humana. No município há muitos agricultores que se declaram agroecológicos com produção orgânica; porém, nenhum deles ainda é certificado.

Analisando os depoimentos dos agricultores beneficiários, observa-se que os 61 cooperados, ou seja $100 \%$, se autodeclararam produtores agroecológicos. Essa questão também influenciada pelo modo de organização dos agricultores. A Coofeliz possui, em seu estatuto, que todo cooperado regular precisa ser, declaradamente, um produtor que não utiliza agrotóxico, limitando o ingresso na organização ao modo de produção adotado. Contudo, os depoimentos da diretora da cooperativa e do técnico da Emater evidenciam que os modos de produção utilizados por esses agricultores não podem ser considerados agroecológicos porque não há certificação e a maioria utiliza adubo químico (o mesmo utilizado no café), descaracterizando, portanto, a agricultura como agroecológica ou orgânica: "Não usamos agrotóxicos. Adubo químico ainda usa um pouco" (Agricultor 29).

Na prática, o modo de produção praticado pelos cooperados são cultivos livres de agrotóxicos, partindo da conscientização pessoal dos agricultores e também das prerrogativas estatutárias da cooperativa. Muitos dos agricultores entrevistados estão em fase de transição em relação ao modo de produção agroecológica. Porém, muito dos plantios são feitos em consórcio com o café, o que deixa exposta a adubação química, uma 
vez que cultivam na mesma lavoura, entre os espaçamentos do cultivo.

É importante destacar que os produtores rurais sentem "orgulho" por cultivarem alimentos livres de agrotóxicos, pois prezam pela qualidade de alimentos destinados aos consumidores que, na maioria das vezes, são parentes ou vizinhos dos que produzem, conforme depoimento a seguir:

[...] Porque primeiramente a gente vê que isso não é bom, a partir do momento que a gente tá jogando o veneno, a gente consome desse alimento e sabe que a gente tá levando para as crianças, igual à feira, a maior parte das pessoas que vai na feira é de pessoas idosas, é uma consciência, questão de saúde (Agricultor 46).

Nos registros de campo, durante as visitas, foi possível perceber a preocupação e, muitas vezes, até a rejeição ao uso de agrotóxico nas propriedades. Alguns agricultores relataram que conhecem diversos casos de óbitos ou doenças no município oriundos do uso intensivo e descontrolado de defensivos agrícolas. Fica nítida a representação negativa que construíram sobre o uso de agrotóxicos.

Constatou-se que a produção livre de agrotóxico para atender o PAA e o PNAE no município ainda não representou nenhum adicional financeiro para essa prática, apesar de que os programas normatizam que produtos orgânicos ou agroecológicos terão um adicional de $30 \%$ em relação ao preço do produto tradicional. A falta e a dificuldade de certificação orgânica fazem os agricultores se submeterem a vender a preço dos alimentos convencionais. A dificuldade de obter a certificação em Espera Feliz assemelha-se à análise de César, Batalha e Pimenta (2008), que relata que o sistema de certificação orgânica feito por auditoria privada apresenta custos elevados de transação, tornando-o muito caro, ou às vezes até inviável para a agricultura familiar.

Nesse panorama, os resultados encontrados nessa seção apontam evidências que os programas serviram para impulsionar a produção livre de agrotóxicos, já que esta era uma prática dos agricultores ligada às crenças, costumes e lutas pela questão agroecológica. Porém, a dificuldade de certificação e, consequentemente, a não valorização monetária dos produtos livres de agrotóxico são vistos como desestimulador para a continuação da produção sustentável.

\subsection{Categoria segurança alimentar}

Na quarta e última categoria, buscou-se conhecer os efeitos dos programas para a segurança alimentar. Para tanto, a discussão dessa categoria está organizada em duas subcategorias: a primeira visa analisar o autoconsumo de produtos alimentares a partir do que é produzido para os programas e a segunda pretende verificar a qualidade dos produtos com base nas exigências que os programas e atores envolvidos colocam.

\subsubsection{Autoconsumo de produtos alimentares}

Gazolla e Schneider (2007) definem o autoconsumo alimentar como aquela parcela da produção animal, vegetal ou de transformação caseira que foi produzida pelos membros da família e que é utilizada na alimentação do grupo doméstico, de acordo com as suas necessidades. Para Chimello (2011, p. 165), a produção para autoconsumo é de grande importância para o suprimento da alimentação familiar, "à medida que representa uma garantia de qualidade dos produtos consumidos pela família; quem produz sabe a procedência dos alimentos, fato que proporciona uma alimentação mais saudável".

A efetivação da compra institucional de agricultores familiares em Espera Feliz resultou em mudanças positivas nas práticas e hábitos alimentares das famílias produtoras. Verificou-se que esse novo mercado impulsiona o autoconsumo, na medida em que parte do que é produzido é retirado para o cardápio familiar. Nesse contexto, alguns depoimentos auxiliam a compreensão desse fenômeno:

A maior parte é produzida aqui; eu busco no mercado mais é sal, arroz, açúcar, mas essas coisas de legume, verdura, fubá, feijão que a gente come, tudo é daqui (Agricultor 24).

Ah! Melhorou muito nossa alimentação! A gente planta bastante tipo de produto né, e acaba tendo de tudo um pouco, a mesa vai ficando mais melhor né. A alimentação melhora, a saúde muda né, entendeu? Isso ajuda muito (Agricultor 12).

Por meio das narrativas, observou-se que há evidente melhora no consumo alimentar das famílias a partir da diversificação e do aumento da produção. 
Para muitos agricultores, o que é comercializado para o mercado institucional é o que sobra, e a prioridade é a alimentação familiar, conforme os relatos "[...] primeiro é a casa, aquilo que passou da quantidade, que nós entregamos, a prioridade é a alimentação" (Agricultor 01). "Nós já tínhamos essa consciência, o que a gente planta, a gente come. O que sobra a gente vende" (Agricultor 22).

Também evidencia-se a relação existente entre a diversificação produtiva e a qualidade da alimentação, que fomenta a segurança alimentar da família dos agricultores familiares entrevistados. Esse resultado vai ao encontro do estudo realizado por Oliveira (2013) no município de Acaiaca e Divino, em Minas Gerais, em que foi apresentado que a diversificação da produção de alimentos possibilitou um cardápio mais variado e nutritivo, o que favoreceu a saúde da família produtora, além de ter reduzido os gastos com a aquisição de alimentos.

A seguir, é apresentado um depoimento que contextualiza os argumentos anteriores sobre o incentivo e melhora da alimentação através do autoconsumo:

Melhorou a alimentação da família, nós plantamos, nós colhemos e pegamos o melhor [...] a gente descobriu que a alimentação de qualidade e boa procedência, faz bem à nossa saúde, a gente alimentando bem, temos mais saúde (Agricultor 22).

Eu tinha parado de plantar moranga, e só de vez em quando eu tinha espinafre. Agora que isso tudo, por exemplo, tem como vender, eu planto mais. E se eu planto mais todo mundo aqui come mais. Assim que tem melhorado, aquilo que eu plantava eu nem provava. Agora o que eu planto a mais eu coloco em casa também (agricultor 35).

Chamou a atenção nas entrevistas a associação feita por diversos entrevistados, relacionando o aumento da produção com a qualidade da alimentação e a saúde da família. Quando questionados sobre o motivo da entrada no mercado institucional, além dos motivos econômicos, vários agricultores enfatizaram a opção "estar vinculada à saúde" que, segundo estes, seria favorecida pelo consumo de alimentos mais saudáveis. Assim, o mercado institucional no município é capaz de criar os benefícios similares aos encontra- dos por Becker et al. (2010) no estado do Rio Grande do Sul, onde foi verificada a relação entre a diversificação produtiva e a qualidade da alimentação no fomento da segurança alimentar das famílias produtoras.

Para Medaets (2003), a produção livre de agrotóxico, agroecológica ou orgânica, sob a ótica ambiental, favorece a diversidade biológica da propriedade e gera impactos diretos sobre o padrão alimentar das famílias na qualidade da água e do solo. As afirmações desse autor também foram confirmadas em Espera Feliz, onde o modo de produção livre de agrotóxico gerou benefícios, além de ambientais, também na melhora da saúde do agricultor e da família.

Percebe-se, portanto, que a produção diversificada de alimentos para o mercado institucional, somada ao cultivo livre de agrotóxico, compõem algumas das principais justificativas que estimulam o autoconsumo entre os entrevistados, uma vez que a preocupação com a saúde foi enfatizada em vários momentos da pesquisa.

\subsubsection{Qualidade dos alimentos}

Entre os itens que compõem a segurança alimentar e nutricional, a qualidade dos alimentos é um dos temas mais importantes para a promoção de saúde de quem os acessa. Em Espera Feliz ficou evidenciado, dentre os representantes de entidades de apoio, o aumento da qualidade dos alimentos, conforme relato abaixo:

[...] acredito que estimulou um aumento na quantidade e diversificação dos produtos da Agricultura Familiar. Os produtores começaram a se organizarem mais, entregando produtos de maior qualidade e de acordo com a necessidade da Escola (Técnico Emater).

Alguns produtos da Agricultura Familiar são de melhor qualidade, apresentando características que geralmente os demais não apresentam, como sabor, aparência do produto, ausência de agrotóxicos etc... (Nutricionista da Secretaria Municipal de Educação).

Também dentre os agricultores que fornecem para o mercado institucional, foi relatado que o aumento da qualidade dos alimentos vem sendo impulsionado pelas exigências de quem compra. As exigências dos 
programas estruturam como elementos coercitivos que buscam padronizar a mínima qualidade dos produtos, o que força os agricultores a se preocuparem em melhorar a qualidade dos alimentos produzidos. A entrevista abaixo destaca essa questão:

[...] nessa última reunião, disse que as verduras serão compradas por peso, aí muitos produtores questionaram, acham que não vai compensar, mas eu já tive pesando minhas verduras, dá sim, porém a gente tem que fazer uma verdura de melhor qualidade (Agricultor 28).

[...] sempre tem reuniões, aí pede para a gente ter mais cuidado, procurar produzir uma verdura e um legume mais bonito, aí sempre pede (Diretora Cooperativa).

Os agricultores familiares e a diretoria da cooperativa têm procurado se ajustar às exigências legais do PAA e PNAE e também às da vigilância sanitária, apesar de encontrarem ainda muitas dificuldades, como o alto custo para implantação e manutenção dos equipamentos. As adaptações às exigências do programa são um fator crucial para a institucionalização deste mercado institucional. Os ajustes às normas legais e a adaptação do modo de operacionalização do programa à realidade local são processos necessários que partem das interações locais e se configuram numa dinâmica social alicerçada nas redes de atores locais.

\section{Considerações finais}

Verificou-se que a implementação do PAA e do PNAE é uma construção social que se edifica no processo de interação dentre os diversos atores que se envolvem com a prática da compra institucional de alimentos. Ficou evidente que, no contexto analisado, os programas induziram o aumento da produção; a atenção à qualidade dos produtos valorizou o trabalho familiar e contribuiu para a diversificação da produção.

De forma geral, os efeitos gerados pelos programas no município estão consonantes com a missão e a visão da Coofeliz de promover maior conscientização ambiental; buscar novas alternativas de produção; trabalhar a produção agroecológica; formação educacional dos sócios; inclusão da mulher e do jovem na renda familiar e oferecer ao consumidor alimento de qualidade. Desta forma, estes programas têm sido ferramentas importantes no estímulo de práticas sustentáveis entre os agricultores e fortalecido os valores que construíram conjuntamente.

Os programas imprimiram novas dinâmicas econômicas e sociais, além de construírem significados aos agricultores beneficiários no município, em que o esforço dos atores envolvidos foi crucial na determinação e efetivação do mercado institucional.

A pesquisa permitiu diagnosticar vários efeitos diretos do PAA e do PNAE junto aos seus beneficiários. O efeito econômico foi verificado com o estímulo à diversificação da produção, aumento de renda, ampliação de postos de trabalho de base familiar no setor agrícola e o acesso a novos mercados. O mercado institucional tem contribuído para o crescimento da produção familiar da agricultura local, incentivando a maior circulação de recursos na economia local e contribuindo para a segurança financeira dos beneficiários e para o desenvolvimento local.

No segundo efeito analisado, o social, observou-se que as compras institucionais têm estimulado o fortalecimento da organização local dos agricultores e ampliado a participação de membros da família, como as mulheres e os jovens. $\mathrm{O}$ arranjo institucional criado com o PAA e o PNAE potencializa a promoção de capital social local em um ambiente com histórico de participação cívica, confiança e ação coletiva para questões voltadas para a agricultura familiar.

Outro efeito importante é o ambiental, que vem se intensificando com a adoção de práticas sustentáveis como a produção de alimentos livres de agrotóxicos. O conjunto de conhecimentos socialmente produzidos pelos agricultores familiares locais, baseados em saberes e métodos tradicionais de respeito ao meio ambiente foi potencializado com a aquisição institucional de alimentos. Porém, é preciso que se criem condições para que os produtos orgânicos sejam certificados e, consequentemente, melhor valorizados financeiramente dentre os compradores.

No último item analisado, a segurança alimentar, verificou-se que o PAA e o PNAE têm contribuindo para a ampliação do repertório alimentar da família, no reforço à prática do autoconsumo de alimentos, melhorando a saúde das famílias dos produtores, auxiliando, assim, o combate à fome e a desnutrição. Verificou-se, também, a melhoria da qualidade dos alimentos a partir das exigências institucionais, uma 
vez que a cooperativa tem se esforçado para que seja garantida a qualidade biológica, sanitária e nutricional dos alimentos.

Observou-se a relevância da integração e coordenação dos dois programas, em que a coesão e interação social entre instituições privadas e públicas, em todos os seus níveis, se mostraram importantes para a efetivação desses programas no município, e vêm gerando benefícios diretos para ambas as partes.

Conclui-se que a identificação de efeitos em cada uma das quatro categorias analisadas indicou que os programas têm contribuído para reforçar o fato de que a agricultura familiar é multifuncional. Além disso, os resultados positivos e sinérgicos desses dois programas confirmaram o caráter inovador dessas iniciativas estatais ao impactarem em diversas frentes do cotidiano da agricultura familiar. As compras institucionais de alimentos via políticas públicas têm potencial para contribuir como importante vetor para o desenvolvimento rural sustentável, principalmente nos pequenos municípios brasileiros, que encontram maiores dificuldades para dinamizar as economias locais.

\section{Referências}

ABREU, K. D. R. A implementação do Programa Nacional de Alimentação Escolar (PNAE) em municípios de pequeno porte: implicações práticas e teóricas. Dissertação (Mestrado) Fundação Getúlio Vargas, São Paulo-SP, 2014, $183 f$.

ALTAFIN, I. Reflexões sobre o conceito de agricultura familiar. UNB. Brasília, 2007. Disponível em: <www. comunidades.mda.gov.br/o/1635683>. Acesso em: 07 mar. 2014.

ALVES-MAZZOTTI, A. J. e GEWANDSZNAJDER, F. O método nas ciências naturais e sociais: pesquisa quantitativa e qualitativa. São Paulo: Pioneira, 1999.

BARDIN, L. Análise de conteúdo. São Paulo: Edições 70, 2011.

BELIK, W. e DOMENE, S. M. A. Experiências de programas combinados de alimentação escolar e desenvolvimento local em São Paulo - Brasil. Revista Agroalimentária, São Paulo, v. 18, n. 34, p. 57, 2012.

BELIK, W. e SILIPRANDI, E. A Agricultura Familiar e o Atendimento à Demanda Institucional das Grandes Cidades In: MAJ, C.; BELIK, W. Projeto Nutre SP: análise da inclusão da agricultura familiar na alimentação escolar no estado de São Paulo. São Paulo: Instituto Via Pública; 2012. p. 61-66.

BONNAL, P.; MALUF, R.S. Políticas de desenvolvimento territorial e multifuncionalidade da agricultura familiar no Brasil. In: CAZELLA, A. A., BONNAL, F. e MALUF, R. S. (Orgs.). Agricultura familiar: multifuncionalidade e desenvolvimento territorial no Brasil. Rio de Janeiro: Mauad X, 2009, P.301.

BRASIL. FNDE. Programa Nacional de Alimentação Escolar (PNAE). Apresentação, 2014a. Disponível em: <http://www.fnde.gov.br/index.php/programas/ alimentacao-escolar/alimentacao-escolar-apresentacao $>$. Acesso em: 25 nov. 2014.

BRASIL. Ministério do Desenvolvimento Agrário (Ed.). Avaliação do Programa de Aquisição de Alimentos (PAA): Resultados das ações da CONAB 2013. Brasília, 2013a. Disponível em: < http://www.conab.gov.br/OlalaCMS/ uploads/arquivos/14_02_18_14_25_08_sumario_ executivo_12.pdf $>$. Acesso em: 09 dez. 2014.

BRUMER, A. e SPANEVELLO, R. M. Jovens agricultores da Região Sul do Brasil. Porto Alegre: UFRGS; Chapecó: Fetraf-Sul/CUT, 2008. Relatório de Pesquisa.

CARNEIRO, M. J. Herança e gênero entre agricultores rurais. Revista Estudos Feministas, Florianópolis, v. 9, n. 2, p. 22-55, jun./dez. 2001.

CAZELLA, A. A., BONNAL, P. e MALUF, R. S. Multifuncionalidade da agricultura familiar no Brasil e o enfoque da pesquisa. In: CAZELLA, A. A., BONNAL, P. e MALUF, R. S. Agricultura familiar: multifuncionalidade e desenvolvimento territorial no Brasil. Rio de Janeiro: Mauad Editora, 2009.

CHIMELLO, R. Fatores determinantes da produção para autoconsumo na agricultura familiar. Unoesc $\mathcal{E}$ Ciência ACET, 2011.

CHMIELEWSKA, D., SOUZA, D. e LOURETE, A. A. O Programa de Aquisição de Alimentos da Agricultura Familiar (PAA) e as Práticas dos Agricultores Participantes Orientadas ao Mercado: estudo de caso no estado de Sergipe. Brasília: IPEA, 2010.

CINTRÃO, R. P. ONGS, tecnologias agrícolas e representação política do campesinato: uma análise entre o Centro de Tecnologias Alternativas e os sindicatos de trabalhadores rurais da Zona da Mata mineira. Dissertação de mestrado em Desenvolvimento, Agricultura e Sociedade no Instituto de Ciências Humanas e Sociais, CPDA da UFRRJ: Seropédica, 1996.

CIRO, P. M. R. e FREITAS, A. F. de. O Programa Nacional de Alimentação Escolar como indutor de Processos de Desenvolvimento Local em Viçosa. In: VII Encontro 
Nacional de Pesquisadores em Gestão Social, 2013, Belém-PA. Anais do VII ENAPEGS, 2013.

DANTAS DA SILVA, K. R. e COÊLHO SILVA, L. A. Análise da comercialização $e$ do impacto do PAA e PNAE na condição de vida das famílias agricultoras de Bananeiras, na Paraíba. Trabalho de conclusão de curso de especialização em Gestão Pública (Economia) Universidade Federal da Paraíba, Paraíba, 2011.

DELGADO, G. C. et al. Avaliação do programa de aquisição de alimentos da agricultura familiar. Brasília: IPEA, 2005.

DORETTO, M. e MICHELLON, E. Avaliação dos Impactos Econômicos, Sociais e Culturais do Programa de Aquisição de Alimentos no Paraná. In: BOTELHO FILHO, F. B. e CARVALHO, A. D. (Orgs.). Avaliação de políticas de aquisição de alimentos. Vol. 7, 27. ed. Brasília: UnB/ CEAM/NER, p. 107-138, 2007.

GAZOLLA, M. e SCHNEIDER, S. A Produção da autonomia: os "papéis" do autoconsumo na reprodução social dos agricultores familiares. Revista Estudos Sociedade e Agricultura, Rio de Janeiro, Ed. da UFRRJ, v. 15, p. 89-122, 2007.

GODOI, C. K., BANDEIRA-DE-MELLO, R. e SILVA, A. B. Pesquisa qualitativa em estudos organizacionais: paradigmas, estratégias e métodos. São Paulo: Saraiva, 2006.

GRISA, C. Políticas públicas para a agricultura familiar no Brasil: produção e institucionalização das ideias. Tese (Doutorado em Ciências Sociais) - Programa de Pósgraduação de Ciências Sociais em Desenvolvimento, Agricultura e Sociedade/UFRRJ, 2012.

. et al. Contribuições do Programa de Aquisição de Alimentos à segurança alimentar e nutricional e a criação de mercados para a agricultura familiar. Revista Agriculturas, Rio de Janeiro, RJ, v. 08, p. 34-41, 2011.

. e SCHNEIDER, S. Três gerações de políticas públicas para a agricultura familiar e formas de interação entre sociedade e estado no Brasil. Revista de Economia e Sociologia Rural, v. 52, p. 125-146, 2014.

HÖFLING, E. de M. Estado e políticas (públicas) sociais. Cadernos Cedes, Campinas, SP: Papirus, no 55, 2001, p. 30-41.

IBGE. Censo Demográfico 2010. Disponível em: <http:// www.censo2010.ibge.gov.br>. Acesso em: 24 mar. 2014.

JANUÁRIO, B.L. A implementação da Lei 11.947/2009 da compra direta da agricultura familiar pelo Programa Nacional de Alimentação Escolar em municípios do estado de São Paulo: possíveis Fatores relacionados. Dissertação (Mestrado). São Paulo: Faculdade de saúde pública da USP, 2013.
KAGEYAMA, A. Desenvolvimento rural: conceitos e aplicações ao caso brasileiro. Porto Alegre: Editora da UFRGS - Programa de Pós-graduação em Desenvolvimento Rural, 2008.

LEITE, S. P. e MEDEIROS, L. S. de. Agriculturas alternativas - dicionário da Educação do Campo. Rio de Janeiro: Editora Fiocruz e Expressão Popular, 2012.

MARTINS, J. de S. Expropriação e violência. São Paulo: Hucitec, 1980.

MATTEI, L. Políticas públicas de combate à fome: o caso do Programa de Aquisição de Alimentos da Agricultura Familiar no Estado de Santa Catarina. Cadernos do CEAM, Brasília, UnB, v. 7, p. 75-105, 2007a.

. Políticas públicas de combate à fome: o caso do Programa de Aquisição de Alimentos da Agricultura Familiar no Estado de Santa Catarina. Cadernos do CEAM, Brasília, UnB, v. 7, p. 75-105, 2007b.

MATTEI, L. et al. O Programa de Aquisição de Alimentos (PAA) em perspectiva: apontamentos e questões para o debate. In: ROMANO, J. e HERINGER, R. (Orgs.). A política vivida: olhar crítico sobre monitoramento de políticas públicas. 1. ed. Rio de Janeiro: Action Aid Brasil, 2011.

PAGANINI, S. A implantação do PAA. In: MDS. Fome Zero Uma História Brasileira. Brasília: editora I-Comunicação, 2010.

PAIVA, J. B. de, FREITAS, M. do C. S. de e SANTOS, L. A. da S. Hábitos alimentares regionais no Programa Nacional de Alimentação Escolar: um estudo qualitativo em um município do sertão da Bahia, Brasil. Rev. Nutr. [online]. 2012, Disponível em: < http:// dx.doi.org/10.1590/S1415-52732012000200002>. Acesso em: 9 set. 2014.

PEIXINHO, A. M. L. A trajetória do Programa Nacional de Alimentação Escolar no período de 2003-2010:relato do gestor nacional. Ciênc. saúde coletiva [online]. v. 18, n. 4, p. 909-916, 2013.

PETERSEN, P. Agriculturas alternativas - dicionário da educação do campo. Rio de Janeiro: Editora Fiocruz e Expressão Popular, 2012.

REINACH, S., CORÁ, M. A. J. e BONDUKI, M. R. P. C. A Inclusão da Agricultura Familiar no Programa Nacional de Alimentação Escolar. In: Anais do XXXVI Encontro da ANPAD. Rio de Janeiro, 22 a 26 de setembro de 2012.

SANTOS, F. P. dos. Coalizões de interesses e a configuração política da agricultura familiar no Brasil. 2011. $182 \mathrm{f}$. Tese (Doutorado) - Curso de Administração Pública e 
Governo, FGV, São Paulo, 2011. Disponível em: < http:// bibliotecadigital.fgv.br/dspace/handle/10438/8211>. Acesso em: 25 nov. 2014.

SCHNEIDER, S. Situando o desenvolvimento rural no Brasil: o contexto e as questões em Debate. Revista de Economia Política, São Paulo, SP, v. 30, n. 3, p. 511-531, 2010 .

., MÜLLER, A. L. e SILVA, M. K. A construção de políticas públicas para a agricultura familiar o Brasil: o programa de aquisição de alimentos. Estudos Sociedade e Agricultura, Rio de Janeiro, UFRJ, v. 20, p. 139, 2012.

TRICHES, R. M. Reconectando a Produção ao Consumo: a aquisição de gêneros alimentícios da agricultura familiar para o Programa de Alimentação Escolar. Tese (Doutorado em Desenvolvimento Econômico) - Universidade Federal do Rio Grande do Sul, Porto Alegre, 2010.

WANDERLEY, M. N. B. Raízes históricas do campesinato brasileiro. In: TEDESCO, J. C. (Org.). Agricultura Familiar Realidades e Perspectivas. 2. ed. Passo Fundo: EDIUPF, 1999.

WEISHEIMER, N. Os jovens agricultores e seus projetos profissionais: um estudo de caso no bairro de Escadinhas, Feliz/RS. Dissertação (Mestrado). Porto Alegre: Programa de Pós-graduação em Sociologia, Universidade Federal do Rio Grande do Sul, 2004. 